\title{
O gênero atuante: a performance de gênero em The passion of new Eve and Goodnight Desdemona (good morning Juliet)
}

Carlos Bento

Resumo:

Este texto usa a performance de gênero, teoria desenvolvida por Judith Butler, para ler algumas partes dos livros The passion of new Eve, escrito pela inglesa Angela Carter, e Goodnight Desdemona (Good morning Juliet), da canadense Ann-Marie MacDonald.

Palavras-chave: gênero, performance, Judith Butler, Angela Carter, Ann-Marie MacDonald

Os estudos de gênero se tornaram, na atualidade, um dos campos de discussão acadêmica mais importantes, graças à relevância que as questões por eles suscitadas alcançam na vida social. Cada vez mais, demandas de gênero são colocadas publicamente, e novas subjetividades reclamam o direito de inserção na esfera pública. Desde o fortalecimento do feminismo dos anos sessenta e setenta do século $X X$, o tema ocupa um lugar de destaque na produção intelectual.

Entre os muitos estudos publicados nas últimas décadas a respeito do gênero, um dos mais influentes é o livro Problemas de gênero, escrito por Judith Butler. Essa obra ganhou notoriedade por compreender o gênero dentro de uma perspectiva construtivista que radicaliza os pressupostos adotados pela crítica, especialmente feminista, até então. Isso ocorre porque Butler afirma que o caráter construtivista não se aplica apenas ao gênero, mas também ao sexo e ao próprio corpo, uma vez que esses dois são significados e normatizados por práticas convencionadas socialmente, principalmente por meio de determinadas práticas discursivas.

A compreensão de que tanto o corpo, quanto o sexo e o gênero são sujeitos à inscrição social leva a autora a desenvolver sua teoria mais importante, a performance de gênero. A teoria surge do cruzamento entre a performance e o gênero, e se desenvolve a partir dos postulados de J. L. Austin a respeito da performatividade da linguagem. Embora essa seja a base inicial da teoria de Butler, a performance de gênero surge do cruzamento de uma série de outros trabalhos teóricos, especialmente a leitura que Jacques Derrida faz de Austin, acrescentando aos trabalhos dele as noções de iterabilidade e citacionalidade. 
A teoria de Austin a respeito da performatividade da linguagem postula que, em situações específicas, atos lingüísticos são capazes de produzir realidades. É o que acontece, por exemplo, quando um juiz profere uma sentença ou um ministro proclama a união matrimonial de duas pessoas. Esses atos lingüísticos criam ou transformam a realidade, gerando conseqüências nos diversos campos da vida social. No caso do matrimônio, por exemplo, a declaração do ministro cria conseqüências em relação à criação de filhos, composição patrimonial, herança, pensão, aposentadoria, etc. De acordo com Austin, para que a realidade enunciada pela linguagem se concretize, no entanto, é necessário que as condições sejam favoráveis. No caso do matrimônio, é necessário que o ministro que proclama a união seja alguém com autoridade para fazê-lo. Caso contrário, a realização do que é enunciado não se efetiva, e a performance é considerada "infeliz".

Em sua leitura da teoria de Austin, Derrida afirma que 0 ato lingüístico performativo só se efetua porque, além das condições adequadas, ele é sustentado pela iterabilidade e pela citacionalidade. Ou seja, a autoridade que permite a concretização do que é enunciado existe porque é repetida ao longo do tempo e em muitos lugares diferentes. Além disso, no momento da enunciação, o falante cita toda a cadeia de seus predecessores que reuniam as mesmas condições favoráveis e que utilizaram a mesma estratégia lingüística, a fim de produzir o mesmo tipo de efeito.

A partir desses pressupostos, Butler afirma que o gênero se produz por um processo performático semelhante ao que se aplica à linguagem na teoria austiniana. Em grande medida, a normatização social em torno do gênero se produz pelo uso lingüístico, o que pode ser visto como uma performance gerando outra. Ou seja, a forma como se usa a linguagem, criando um discurso coercitivo em relação ao gênero, é performática porque produz uma realidade, criando limites e regras para sua expressão. Simultaneamente, garante o caráter performático do próprio gênero, pois este se cria ao mesmo tempo em que é normatizado. Referindo-se ao conceito de interpelação de Louis Althusser, Butler afirma que o gênero começa a ser regulado desde que se anuncia que um bebê é "menino" ou "menina". Afinal, esse anúncio determina uma cadeia de atos que visam a moldar o gênero e a forma como o indivíduo viverá sua sexualidade. Haverá controle sobre o tipo de roupas que a criança poderá usar, as cores, os brinquedos, etc.

A teoria de Butler a respeito da performance de gênero tem inspirado muitos estudos e debates, em vários campos disciplinares. Uma das aplicações possíveis é o seu uso para mediar a leitura de obras literárias que apresentam histórias que discutem questões de gênero. Aqui, trata-se de duas obras particularmente apropriadas para pensar o gênero a partir de seu caráter performático: The passion of new Eve, da escritora inglesa Angela Carter, e Goodnight Desdemona (good morning Juliet), da canadense Ann-Marie MacDonald.

Escritas em países e épocas bastante diferentes, essas duas obras lidam com questões de gênero de maneira bastante peculiar, pois o representam de maneira fortemente performática. Carter narra a história de Evelyn, um professor inglês que viaja para os Estados Unidos a fim de lecionar em uma universidade. É seqüestrado por uma guerrilha de mulheres que o conduzem até uma cidade subterrânea chamada de Beulah. Nesse local, Evelyn é submetido, à força, a uma cirurgia que muda seu 
sexo, fazendo dele uma mulher, que passa a se chamar Eve. A partir de então, ele é obrigado a aprender a ser uma mulher.

O livro de MacDonald conta a história de Constance, uma professora assistente em uma grande universidade canadense, que tenta terminar sua tese de doutorado. No dia do seu aniversário, ela é levada para dentro das peças Romeu e Julieta e Otelo, passa a conviver com suas personagens, e impede a morte das heroínas Julieta e Desdemona. Assim, reflete sobre sua vida e sua condição de mulher.

O livro de Carter apresenta uma visão clara do caráter construtivista e performativo do gênero. O corpo de Evelyn é usado como um suporte no qual se inscreve o script formal do gênero feminino. Esse script formal, morfológico, anatômico, é complementado por um outro, social, que é o treino psicológico, a etapa da cirurgia que visava a treinar a nova mulher surgida do bisturi da Mãe. Há ainda Tristessa e Zero, duas personagens que exemplificam bem o caráter lingüístico e o teatral da construção performativa do gênero. Zero é um tirano machista que mantém um harém de mulheres, ao qual Eve é integrada. Tristessa é uma musa do cinema, admirada por Evelyn, que ao fim se revela travesti. O livro de MacDonald discute a questão de duas maneiras principais: primeiro por meio da viagem de auto-descoberta de Constance, que revela o quão arbitrária e violenta é a estrutura social do gênero; depois, comicamente, por meio da deliberada troca de identidades de gênero praticada por Romeu e por Julieta.

A cirurgia que muda o corpo de Evelyn necessita a complementação de uma terapia psicológica, que visava a criar nele/a uma psiquê feminina. Em Beulah o gênero é construído por meio da imitação, do aprendizado. Trata-se, portanto, de um treinamento para atender às exigências sociais. Como Eve foge de Beulah antes que a terapia esteja completa, as mulheres de Zero tornam-se um modelo para ela. Como estava em fase de aprendizado, era constantemente atormentada pelo medo de não se comportar como era esperado de uma mulher, o que revela como a noção contida no livro, que reinava em Beulah e na cabeça da nova mulher de Zero, era de que o gênero não passava do cumprimento de um script socialmente determinado. Trata-se de um aprendizado, de um treinamento, nos moldes da performance de Butler. 0 caráter performático do treinamento de Eve fica ainda mais claro quando ela afirma: "embora eu fosse uma mulher, agora eu estava também passando por uma mulher, mas, então, muitas mulheres de nascimento passam suas vidas inteiras simplesmente com tais imitações" (CARTER, 1992, p. 101). Portanto, estendendo sua experiência para outras mulheres, Eve constata que o feminino, o gênero, é composto por camadas: é preciso ser mulher no sentido biológico, e é preciso passar-se por mulher, ou seja, encenar o papel feminino, como se fosse um teatro. O gênero, desse ponto de vista, é performático não apenas porque se forma a partir das construções sociais, mas também porque exige a atuação do indivíduo, que precisa agir de acordo com um roteiro pré-estabelecido e imposto, e não em função, necessariamente, do seu sexo biológico.

Evelyn tinha como musa uma estrela de cinema chamada Tristessa, odiada por Zero, que a caçava obessivamente para matá-la. Quando ele invade o palácio de vidros e espelhos onde Tristessa residia, Eve a encontra, em uma cena que apresenta inúmeros elementos performáticos. A descoberta do sexo de Tristessa - masculino revela não apenas o caráter de construção do gênero, mas também a radical 
separação entre as duas categorias. Tristessa encenara o gênero feminino por toda a vida, sendo considerada um modelo perfeito de mulher. A perfeição, nesse caso, é atribuída, por Eve, ao fato de ela ser um homem. Portanto, é pela noção masculina a respeito da femininidade que se pode chegar à perfeição da mulher. Aqui, as duas identidades de Tristessa, como discutido a respeito de Eve um pouco antes, se opõem. Ela encena uma identidade que é diferente daquela denunciada pela forma corporal. Não é à toa que o travestismo é considerado por Butler como uma forma performática de subversão da normatividade impositiva do gênero. Na cena do casamento entre Eve e Tristessa, além de toda a encenação teatral e do complexo jogo de gênero, em que Eve é obrigada a voltar ao papel masculino, e Tristessa, que tem um corpo masculino e se apresenta como mulher, é obrigada a assumir o papel feminino, há uma rendição ao modelo de performance lingüística de Austin. Zero se constitui ministro da cerimônia, que inclui a colocação das alianças, com o tirano proclamando Eve e Tristessa como marido e mulher. Em tese, ocorreria, neste caso, o que prescreve a teoria austiniana. Porém, claro, tudo não passa de uma falsa cerimônia, e portanto não há condições para que a performance seja feliz. Afinal, as condições preconizadas por Austin não estão presentes, uma vez que Zero não é investido de autoridade que the permita realizar casamentos. Além disso, o casal em questão não cumpre nenhum requisito social para serem declarados como marido e mulher, incluindo o fato de que não se dispuseram a tanto de maneira voluntária. No mais, a própria narrativa mostra que as conseqüências advindas daquela cerimônia grotesca não são, em nada, aquelas esperadas de um matrimônio. Zero estupra Tristessa e a pendura no teto, esperando sadicamente o momento de matá-la.

Finalmente, é preciso considerar que, no final, é oferecida a Eve a alternativa de reversão da cirurgia. Assim, Carter parece sugerir que o corpo, o sexo, o gênero podem ser inscritos e reinscritos, passados a limpo, modificados ao infinito. Uma possibilidade, no plano prático, de que os gêneros podem ser vivenciados performativamente, numa liberdade quase absoluta. Porém, claro, como fica evidente no curso da narrativa, essa liberdade não passa de uma possibilidade, uma vez que o roteiro a ser seguido é definido arbitrariamente e imposto aos indivíduos, que não podem optar por recusá-lo, sob pena de serem condenados à abjeção e ao apagamento social. Desde o início, com a construção da masculinidade em Evelyn, até a cirurgia e o aprendizado da condição feminina, fica claro que o corpo é um espaço natural, biológico, que depende, para sua existência prática, da inscrição social. A forma, porém, como tal inscrição se impõe, não é outra coisa além de violenta, sádica, e repressora.

No livro de MacDonald, o caráter performático do gênero se torna bastante evidente na parte que narra a convivência de Constance com Romeu e com Julieta. Constance entra na trama de Verona exatamente no momento em que Mercutio e Tybalt lutam. Romeu interpela Constance, dizendo: "Fala, garoto... fala garoto" (MACDONALD, 1998, p. 50). Essa interpelação fará com que a garota seja vista como garoto por todo o tempo em que fica em Verona, até o momento em que, no final, ela se revela para Julieta. O fato é que ela própria toma a fala de Romeu como realidade para aquele momento, sustentando a idéia de que era homem. Dessa forma, a fala de Romeu pode ser associada tanto à performance lingüística de Austin quanto à interpelação de Althusser. Afinal, chamar Constance de garoto foi suficiente para 
estabelecer uma cadeia de significados em torno dela. A forma como as outras personagens se relacionam com ela passa a ser determinada pelo gênero presumido pela palavra garoto. Um pouco à frente, Romeu se refere a ela como "Bravo grego!" (MACDONALD, 1998, p. 51). Novamente, a interpelação de Romeu é capaz de interferir na realidade, conferindo a Constance, que passa a ser chamada de Constantine, o caráter de ambigüidade sexual. A partir daí, a confusão entre os gêneros, os sexos e as formas de sexualidade fica cada vez maior.

A confusão de gêneros, na peça, vale-se da atração que Constance consegue despertar tanto em Julieta quanto em Romeu. Tudo começa em um baile de máscaras na casa dos Capuleto. Quando Romeu vê Constance, ele a abraça com força e a olha de maneira apaixonada. Questionado sobre sua relação com Julieta, ele responde, de maneira surpreendente: "Não fale de Julieta, pois é você que eu amo" (MACDONALD, 1998 , p. 61). Então, Romeu se ajoelha aos pés de Constance, afirmando que mudaria de sexo, caso esse fosse o impedimento para a união dos dois. Ao fim, Romeu beija Constance, à força. Neste momento, chega Julieta. Quando ela e Constance se apresentam, a situação se repete, de forma semelhante ao ocorrido com Romeu. Julieta se encanta imediatamente com o suposto rapaz grego. Resoluta, após conversar brevemente com Constance e conduzi-la numa dança, Julieta também decide trocar sua identidade sexual, a fim de tornar possível o romance almejado.

A razão da confusão é simples: Constance fora identificada como sendo um rapaz, o que gerou toda uma cadeia de expectativas em torno dela, bem como toda uma rede de significações em torno do que ela fazia ou dizia. A esse fato se soma a idéia de que ela viera da Grécia, o que evocou o ideário em torno da ambigüidade sexual. Assim, Romeu acredita que o rapaz seja heterossexual, ao passo que Julieta o vê como homossexual. Isso tornaria qualquer tipo de envolvimento amoroso com Constance inviável tanto para Romeu quanto para Julieta. O que não é simples e surpreende é a solução imaginada pelas duas personagens de Shakespeare, que pensam imediatamente em trocar suas identidades sexuais. Para o leitor é ainda mais interessante perceber que os dois julgam ser possível mudar sua sexualidade apenas invadindo o guarda-roupas um do outro e trocando as roupas.

A atitude dos dois jovens revela a forma como, na peça, se concebe o gênero, ou seja, como um artifício social, baseado em ritos e em disfarces, em aparências. Parece claro que apresentar-se como homem é suficiente para sê-lo, da mesma forma que apresentar-se como mulher é suficiente para tornar-se uma. Isso se revela desde o momento inicial em Verona, quando Constance é percebida como homem. A partir daí, nenhuma das personagens com quem ela tem contato faz qualquer tipo de ressalva ou de questionamento em torno dessa identidade presumida. Quanto a Romeu e Julieta, ambos sugerem que as roupas, a aparência, são suficientes para constituir ou alterar a identidade de gênero. Uma maneira teatral de se conceber o gênero, ou, antes, uma forma de revelar o aspecto teatral da sua construção. Esse aspecto teatral compõe a teoria da performance do gênero de Butler, que a concebe como uma fusão da atuação e da determinação lingüística. Mesmo sabendo-se que, no fim, Constance se revela para Julieta e nem esta nem Romeu são agraciados com um romance com a acadêmica, a disposição de ambos não deixa dúvida de que o gênero, ali, é construído por um processo performático. 
Os dois livros aqui discutidos são, assim, exemplares da aplicação da teoria de Butler sobre a performance de gênero. Sua teoria responde a questionamentos teóricos muito pertinentes no atual contexto sócio-histórico e cultural. No entanto, é importante notar que a própria autora admite que vem mudando suas idéias graças, principalmente, aos questionamentos feitos em relação ao seu trabalho. À crítica, se quer receber tal nome, compete utilizar a teoria para perceber as falhas internas que ela apresenta, a fim de aprimorá-la cada vez mais, para cumprir seu papel de ação política. Quanto ao gênero, há na atualidade uma situação dupla, na qual ao mesmo tempo em que se percebem grandes avanços, há a necessidade do reconhecimento de que há muitas demandas e direitos a conquistar. A contribuição de Butler e da leitura que se faz aqui, a partir de sua teoria da performance de gênero, das obras de Carter e MacDonald, contribuem para a discussão, mas não são, de forma alguma, nenhum tipo de solução. É preciso utilizar esses trabalhos para refletir, e a partir da reflexão, oferecer subsídios que se constituam em ferramenta para a mudança de uma situação que, como se viu, serve a propósitos opressores inaceitáveis quando se pensa, como Butler vem fazendo, no caráter humano que nos constitui.

Abstract:

Gender performance, a theory developed by Judith Butler, is used to read parts of the books The Passion of New Eve, by Angela Carter, and Goodnight Desdemona (Good morning Juliet), by Ann-Marie MacDonald.

Keywords: gender, performance, Judith Butler, Angela Carter, Ann-Marie MacDonald

Referências

AUSTIN, J. L. How to do things with words. Cambridge: Harvard University Press, 1967.

BUTLER, Judith. Problemas de gênero: feminismo e subversão da identidade. Trad. Renato Aguiar. Rio de Janeiro: Civilização Brasileira, 2003.

CARTER, Angela. The passion of new Eve. Londres: Virago, 1992.

DERRIDA, Jacques. Limited Inc. Evanston: Northwestern University Press, 1988.

MACDONALD, Ann-Marie. Goodnight Desdemona (good morning Juliet). Toronto: Vintage, 1998. 